\title{
Predicting Bicycle Theft in Milan (IT): An Aoristic Analysis
}

\author{
Giacomo Salvanelli ${ }^{1} \bowtie$
}

\begin{abstract}
Local administrations keep creating policies to promote cycling among citizens. However, these initiatives seem to be often counterproductive for the targeted objectives because of the increase opportunities for bike-theft. So, this research aimed at exploring Milan (IT) as a case study to address temporal distribution of bike-theft at the meso-level while controlling for seasonal variation. The occurrence of certain timeframes was evaluated against the distribution of bicycle theft between 2011 and 2015 and predictive risk effects were estimated using the Aoristic analysis. The latter provided a temporal weight and gave an indication of the probability that the events occurred within a defined period between 2016 and 2018. Within this timeframe, the Aoristic analysis showed a higher level of risk stemming from specific days of the week and times of the day, which indeed were responsible of $76 \%$ of the registered bikethefts. The results of this study point to temporal elements that need to be taken into consideration while formulating policies that promote an urban crime-controlled environment for cyclists in Milan. Indeed, since many common crimes are aoristic, techniques such as the Aoristic analysis is crucial for ensuring an effective deployment of resources at the right time to prevent crime.
\end{abstract}

Keywords: bicycle theft, Milan, cycling, aoristic analysis

\section{\Contact email: giacomo.salvanelli@misapinstitute.com}

\section{(G. Salvanelli)}

1 MISAP, Multidisciplinary Institute for Security management and Antisociality Prevention, Milan, Italy

Received: 10 August 2019. Accepted: 12 November 2019.

\section{Introduction}

The routine activities approach to explaining crime patterns, first developed by Cohen and Felson (1979, 590), describes how variations in the availability of guardians, offenders and targets can be used to explain spatio-temporal variations in crime. In case of the presence of offenders, several targets and no guardians, there is likely to be more crime (Brantigham \& Brantigham, 1993, 6). In this respect, academic interest in theorizing and then developing new crime-analysis techniques has mainly dealt with spatial patterns of crime (Ratcliffe \& McCullagh, 1998, 752), with less interest in temporal variation. This does not mean that the latter is not relevant, Felson $(2006,7)$ indeed described offending behavior as being "in motion-daily, hourly, and momentarily, on large scale and small", while Felson and Poulsen (2003, 595) revealed that crime patterns tend to vary more throughout each day than in any other timeframe.

Existing literature showed that the routine activities approach can explain temporal patterns of crime. The latter can be analyzed at different levels: yearly, monthly and weekly (Baumer \& Wright, 1996); but the highest attention is paid to variations across the day as our scale of interest here. For example, Melbin $(1978,453)$ found that crime patterns in Boston substantially followed a routinely framework. Cohn $(1993,76)$ noted that some factors such as the time of the day, public holiday, school vacations and day of the week predicted the frequency of police calls to report domestic violence. Messner and Tardiff $(1985,258)$ found that homicides involving people who knew each other were more common at weekends, when people spend more time with friends and family members. Once more, Cohn and Rotton $(2003$, 356) took this assumption and verified that several crime patterns vary substantially on major public holidays, when both victims and offenders are involved in activities that differ from everyday life actions. These researches all reveal that time-variations in crime are both significant and linked to the routine activities of offenders and victims.

This assumption is particularly true for property crimes as well. Indeed, several studies revealed the importance of time in scheduling the occurrence of crimes such as burglaries (Ratcliffe, 2000), auto thefts (Krimmel \& Mele, 1998), shoplifting (Savona et al, 2019) and bicycle theft (Zhang et al, 2007; Johnson et al, 2008; Sidebottom et al, 2009). However, despite its economic and environmental impact on the local communities, bicycle theft has not been sufficiently addressed from a temporal point of view by the research. In fact, some researches deliberately focused solely on the geographical distribution of bike-thefts in order to identify potential urban risk-factors acting as crime's triggers (Mburu \& Helbich, 2016). However, as far as it is known by the author, no researches have taken into consideration its temporal dimension from an aoristic perspective. 


\section{The present study}

With the rapid changes caused by urbanization and motorization processes, urban mobility and accessibility are facing a substantial decline in several western countries (Gakenheimer, 1999; Sudhakara Reddy et al., 2012). The latter are unsurprisingly displaying an increasing number of issues related to urban mobility, such as insufficient transport facilities, mode shift from public to private transport, traffic congestion (Gakenheimer, 1999; da Silva et al., 2008; Sudhakara Reddy et al., 2012). Moreover, the increasing use of private transport brings about negative consequences, including air pollution, traffic accidents and traffic congestion.

That is the reason why the concept of sustainable transport objectives started to centralize the attention of local administrations. Sustainable transport objectives refer to any strategy put in force to favor the deployment of transports with fuel-efficient, space-saving and healthy lifestyle, and call for an equilibrium between the resources needed by present and future generations to rely upon this type of transportation (Han, 2010; Richardson, 2005). Particularly, non-motorized transport modes are seen as the real lifeblood of sustainable transport (Rietveld \& Daniel., 2004), especially the bicycle being defined as "the individual non-motorized transport mode that is associated with the benefits in terms of environment, society and economy" (Jensen et al., 2010; Pucher et al., 2010; Vandenbulcke et al., 2011).

In this respect, it is not surprising that local administrations are increasingly advocating policies to promote cycling among citizens. Indeed, the benefits of cycling to the environment and to personal health are well known and established among the community members (Mburu \& Helbich, 2016; Vandenbulcke et al, 2011). As a consequence of this increasing interest in healthy transportation systems, researchers started to extensively study the potential dangers faced by cyclists, such as injury, exposure to carbon monoxide and cardiac disease (Winters et al, 2010; Montani et al, 2015). However, despite this large part of the literature, local administrators grapple with a less explored risk related to cycling, namely bicycle theft.

In this respect, international evidence shows that bicycle owners are three times more likely to lose possession through theft compared to owners of motorcycles and cars (Zhang et al, 2007; Johnson et al, 2008; Sidebottom et al, 2009). This data goes back to the broader concept of repetitive victimization, which greatly undermines policies to promote cycling because a large proportion of victimized individuals neither resume cycling nor replace their stolen bicycles (Koetse \& Rietveld, 2009). Several countermeasures have been put in place to reduce bike theft, such as safer locking mechanisms, better parking facilities and interventions that target high risk urban areas (Sidebottom et al, 2009). However, while these interventions might have contrasted crime occurrence, bicycle theft has not been thoroughly analysed to date from an aoristic point of view (Mburu $\&$ Helbich, 2016). For example, research in Italy has yet to examine when bicycle thefts have most commonly occurred, and as such no research to date has investigated the relevant temporal patterns in the thieves' behaviour.

Thus, despite the efforts to contrast bicycle theft, police may face an increase in the community's lack of confidence in their capacity to recover the stolen items (Gamman et al, 2004). For instance, statistics based on the cases that occurred between 2013 and 2016 for Milan showed that every day almost 50 bikes were stolen, but only $40 \%$ of the victims reported it (FIAB, 2018). These findings were similarly retrieved from London (between 2013 and 2016), showing that perpetrators of 96 percent of the reported bicycle thefts are as yet unidentified (Mburu \& Helbich, 2016). In this respect, a major focal concern is therefore to identify, analyse, and target those specific timeframes that can increase victimization probabilities in urban contexts.

The present study, which wants to be the initial step of a deep research's path, adopted an aoristic analytical method to verify its predictive capacity of future crimes. The contradistinguishing way of assessing the validity of both crime data and method was whether or not they actually reflect the circumstances faced by police officers on a daily basis.

More precisely, this research used data on bicycle thefts in Milan as a case study, which are aoristic and none of them have occurred in either of two units of analysis.

The central aim of this study was therefore to verify if the aoristic analysis estimation method of crimes occurred between 2011 and 2015 predicted the temporal distribution of bicycle thefts that took place in the following three years (2016-2018). Within that framework, the research aimed at answering two important questions:

1) Did bicycle theft display stable temporal patterns?

2) Is Aoristic analysis accurate at identifying high risk timeframes for bike-thefts?

\section{Methods \\ Study Area}

This research took place in Milan as the capital city in the county of Lombardia with a total estimated population of 1.352.000 inhabitants (Censis, 2018). Bicycle theft is prevalent in the city (Submarine, 2019), and although the entire metropolitan area experiences substantial risk, 70 percent of all incidents between 2011-2018 were reported in Inner Milan (Submarine, 2019). It supposedly happened because of the interplay of risky places and increased human interactions underlying the crime concentrations. Indeed, Inner Milan comprises many bars, tram stations and commercial facilities, all of which attract crowds for reasons unrelated to crime but nevertheless could provide opportunities for bicycle theft. Within this urban framework, it was argued that bike-thefts tend to display relevant temporal patterns (on a monthly, weekly and daily basis). 


\section{Data Collection}

Data was collected via both the Rubbici database (Rubbici, 2019), and the Registro Italiano Bici (RIB) ('The Italian Bike Registry') (Registro Italiano Bici, 2019). The Local Police Force of Milan was partially involved in this research because it did have access to a limited dataset including only 221 bike-theft records, which was not sufficient to run a statistically significant Aoristic analysis. Therefore, the authors decided to identify other available online platforms such as Rubbici and RIB for data collection. They are open databases where citizens independently report any bike-theft they have directly and/or indirectly experienced.

In other words, these are open databases collecting thousands of bicycle theft reports at a local level. Each of them includes several details such as crime's address, time, date, bike's model, security measures in place when stolen, as well as the victims' personal information including gender and age. In this respect, the final dataset comprised 1.894 both spatially and temporally referenced bicycle theft incidents that were recorded over 8 years (between November 2011 and December 2018). In regard to this, approximately 300 cases were crossed out from the final dataset because they were lacking of sufficient information about the crime's address and time of occurrence, which meant no possibility to track down the crime event to a specific time and location.

\section{Materials}

Quantum Geographical Information System (QGIS) was used to create and use crime maps, compile geo-data, analyze already existing mapped information, and manage geographical information. More precisely, QGIS brought multiple sources of data together by connecting them to the environment. In addition, Microsoft Excel was used to perform Aoristic analysis of bike-thefts at a meso-level to give indications of the probability that the events occurred within a defined period.

\section{Aoristic analysis}

Knowing when crime occurs is fundamental for any analysis of crime, but it is also challenging for certain crime categories where the crime analyst does not know when individual incidents occurred. Ratcliffe and McCullagh $(1998,754)$ call these "aoristic crimes", using a Greek-derived word meaning "indeterminate". This is often problematic for police officials, as determining the time of an offence is difficult. As such this may explain why the police shift their focus to where the crime has occurred, as this information is more readily available (Ratcliffe, 2000).

In that sense, most crimes against property can be considered aoristic, while most crimes against people cannot. For example, someone who got robbed or assaulted will have enough information to share with the police in regard to the exact time and location of crime, because he or she has directly experienced it, on the contrary, the victim of a bicycle theft will often only be able to state:

1. The time at which the victim left the bicycle unattended. This is defined as the earliest time at which the crime could have occurred, hereafter known as Tstart;

2. The time at which the victim got back to find out that the bicycle was stolen. This is known as the latest time at which the crime could have happened, hereafter named as Tend.

Tend - Tstart $=$ Trange , the timeframe during which the bike-theft could have occurred (Ashby \& Bowers, 2013). Trange might be few minutes, hours or maybe weeks, depending on how long the victim left the bicycle unattended for (Ashby \& Bowers, 2013).

\section{Why Aoristic analysis?}

Aoristic analysis provides a temporal framework for when a specific crime is more likely to be taking place. More precisely, this method attributes a 1-point value to each crime event and assigns an equal fraction of that value to each unit of analysis in which the offence could have happened (Ashby \& Bowers, 2013). In other words, if a crime event has taken place within 10 hours, aoristic method would assume that there is a probability of 0.1 that the offence occurred in any single hour-long period (Ashby \& Bowers, 2013). The distribution of Taoristic would be the sum of all the fractions allocated from each crime to each hour (Ashby \& Bowers, 2013).

\section{Ethics}

The research was conducted ethically according to international standards as described in Harriss and Atkinson (2011); therefore, it meets the ethical standards of the journal.

\section{Results}

The principal objective of this research was to evaluate the potential effect of temporal patterns on the registered bicycle thefts between November 2011 and December 2018 .

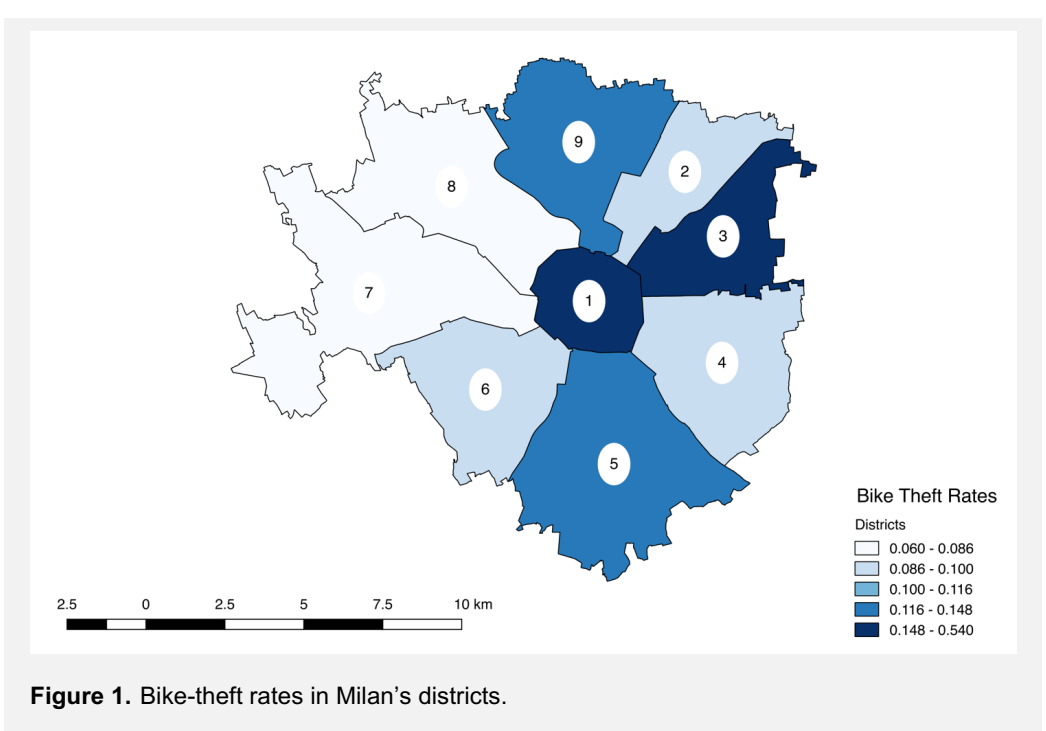


All of the coded crime events covered an area of approximately $181,67 \mathrm{~km} 2$. Descriptive statistics were performed to examine both the geographical and temporal distribution of bicycle thefts across the nine districts of Milan. Figure 1 shows that crime events occurred in the entire urban area of the city, however, some districts, respectively districts $1(0,54), 3(0,19)$ and $9(0,12)$, displayed higher biketheft rates compared to the others $(2=$ 0,$09 ; 4=0,10 ; 5=0,11 ; 6=0,10 ; 7=$ $0,08 ; 8=0,06)$.

The distribution of crime events revealed a seasonal variation across months. More precisely, the vast majority of bicycle thefts clustered in two specific seasons of the year, namely summer and autumn which accounted for $63 \%$ of total crime $(\mathrm{N}=$ 1195). Spring was responsible of $27 \%$ of total bike-thefts registered in Milan $(\mathrm{N}=511)$. On the contrary, winter seems to be the least statistically significant period of time, gathering $10 \%$ of total crime records $(\mathrm{N}=188)$.

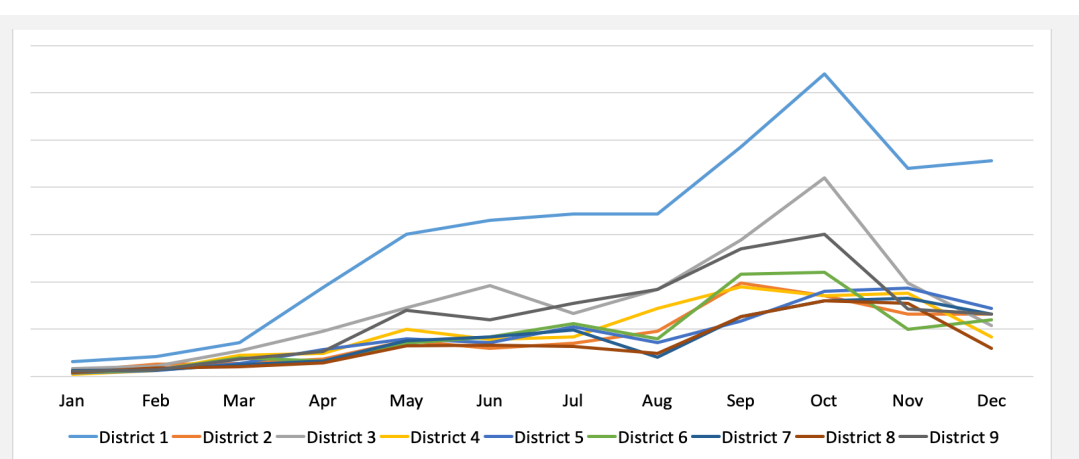

Figure 2. Monthly distribution of bicycle thefts in Milan.

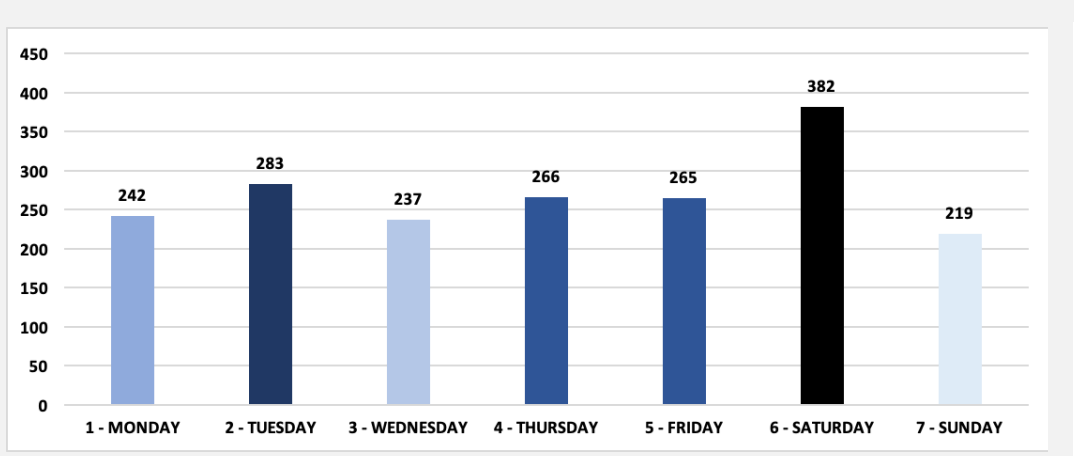

Figure 3. Weekly distribution of bicycle thefts in Milan.

Figure 2 shows the seasonal variation of bicycle thefts in Milan.

On a weekly basis, bicycle thefts occurrence revealed an almost stable distribution. More precisely, 20.2\% of them occurred on Saturdays $(\mathrm{N}=382), 14.9 \%$ on Tuesdays $(\mathrm{N}=283), 14 \%$ on Thursdays $(\mathrm{N}=266), 14 \%$ on Fridays $(\mathrm{N}=265), 12.8 \%$ on Mondays $(\mathrm{N}=242)$, $12.5 \%$ on Wednesdays $(\mathrm{N}=237)$ and $11.6 \%$ on Sundays $(\mathrm{N}=219)$. Figure 3 shows the weekly distribution of bicycle thefts in Milan.

Furthermore, bicycle thefts displayed a relevant temporal distribution during the day. More precisely, $34,7 \%$ of those crimes took place between $8 \mathrm{am}$ and $1 \mathrm{pm}$ $(\mathrm{N}=658), 14,5 \%$ between $1 \mathrm{pm}$ and $7 \mathrm{pm}(\mathrm{N}=274)$, $20,9 \%$ between $7 \mathrm{pm}$ and midnight $(\mathrm{N}=396)$, and $29,9 \%$ between midnight and $8 \mathrm{am}(\mathrm{N}=566)$. This trend was confirmed for 8 districts out of 9 . Indeed, for district 1 ,
$26,8 \%$ of bike-thefts were reported between $7 \mathrm{pm}$ and midnight, showing a diverse displacement of crime when compared with the other precincts. Figure 4 shows the temporal distribution of bicycle thefts between November 2011 and December 2018 for each district.

Afterwards, an Aoristic analysis was performed for bikethefts which occurred between 2011- 2015 to test its predictive capacity of bike-thefts that have actually happened in the following three years (2016-2018). In this respect, a 1-point value was given to each crime event, and an equal fraction of that value was assigned to each unit of analysis in which the offence could have happened. The distribution of Taoristic was particularly high for certain timeframes during some days of the week. More precisely, the within day Aoristic risk values $(\mathrm{RV})$ were the following (see Figure 5):

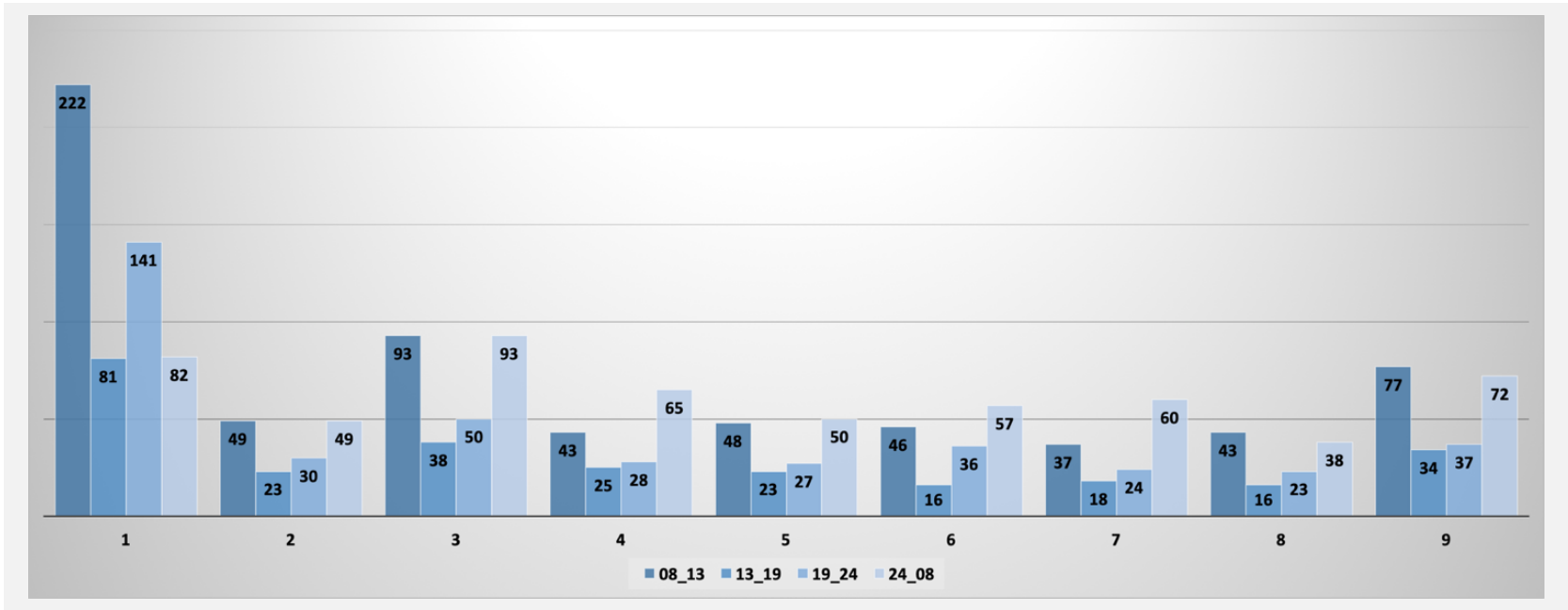

Figure 4. Daily distribution of bicycle thefts per district. 
- Mondays from 9:00 to 12:30 $(15,79<\mathrm{RV}<16,05)$;

- Tuesdays from 08:00 to $12: 30$ $(20,52<\mathrm{RV}<20,87)$;

- Wednesdays from both 9:00 to $12: 30(23,09<\mathrm{RV}<23,48)$ and 19:00 to $22: 30(11,05<\mathrm{RV}<$ 11,24);

- Thursdays from 08:00 to $12: 30$ $(20,13<\mathrm{RV}<20,47)$;

- Fridays from both 08:00 to $12: 30$ $(9,87<\mathrm{RV}<10,03)$ and $19: 00$ to $22: 30(24,47<\mathrm{RV}<24,88)$;

- Saturdays from both 08:00 to $12: 30(14,01<\mathrm{RV}<14,25)$ and $19: 00$ to $22: 30(15,79<\mathrm{RV}<$ $16,05)$;

- Sundays from both 00:00 to 08:00 $(18,97<\mathrm{RV}<$ $19,29)$ and 19:00 to $22: 30(21,31<\mathrm{RV}<21,67)$.

The accuracy of this procedure, using the risk value for each estimation of the Aoristic analysis, was measured by considering what proportion of the identified Tranges overlapped with actual bicycle thefts registered between 2016 and 2018. Table 1 shows the results and confirms the estimation provided by the Aoristic analysis method, indeed, it revealed that $76 \%$ of bike-thefts that have occurred between 2016 and 2018 actually fallen within the Tranges identified as high-risk.

More precisely, $45 \%$ of the registered bike-thefts has took place between 08:00 am and 12:30 pm on Monday(s), Tuesday(s), Wednesday(s) and Thursday(s), which were indeed identified as particularly risky by the Aoristic analysis (see Table 1). Similarly, $12 \%$ of total crime happened between 19:00 pm and 22:30 pm on Friday(s), which were again seen as significantly vulnerable timeframes (see Table 1). Equivalently, 19\% of all registered bike-thefts has fallen between 19:00 pm and 22:30 $\mathrm{pm}$ as predicted by the Aoristic analysis (see Table 1).

\section{Discussion}

The results show that bicycle thefts followed specific temporal patterns across the city of Milano.

From a general point of view, bike-theft displayed a relevant seasonal outcome as $63 \%$ of crimes occurred between Summer and Autumn. One possible explanation might be the weather conditions. Indeed, they are notoriously good seasons in terms of temperature and climate stability and that could give to cyclists more opportunities to ride their bike outdoor

Table 1. Aoristic analysis optimal Tranges deployment period.

$\begin{array}{lccc}\text { Method } & \text { Days } & \text { Tranges } & \begin{array}{c}\text { Percentage of thefts } \\ \text { (2016-2018) that } \\ \text { fallen within those } \\ \text { days/Tranges }\end{array} \\ \text { Aoristic } & \text { Monday } & 08: 00-12: 30 & 10 \% \\ \text { Analysis } & \text { Tuesday } & 08: 00-12: 30 & 16 \% \\ & \text { Wednesday } & 08: 00-12: 30 & 8 \% \\ \text { Aoristic } & \text { Thursday } & 08: 00-12: 30 & 11 \% \\ \text { Analysis } & \text { Friday } & 19: 00-22: 30 & 12 \% \\ & \text { Saturday } & 19: 00-22: 30 & 19 \%\end{array}$

instead of using motorized transportations. However, as a logical consequence, more bicycles on the streets means an increased level of crime opportunity for bikethieves.

On a weekly basis, results showed that bike-theft tend to cluster especially during the last days of the week (Thursday(s), Friday(s) and Saturday(s)), however, significant differences in terms of within day temporal distributions between the city's districts were elicited. In regard to this, relevant information was retrieved thanks to an Aoristic analysis of bicycle thefts which occurred between 2011 and 2015. This identified specific days and timeframes (Tranges) as high risk for bike-theft, which indeed predicted $76 \%$ of the registered crimes that occurred between 2016 and 2018. However, it is important to stress that the aoristic method did not assume that each crime occurred at a specific time but rather within a known Trange, and this may explain the high predictive capacity of the aoristic analysis on this occasion.

In regard to Trange-a (08:00 - 12:30), as previously mentioned, risk values seemed to be particularly relevant for Mondays, Tuesdays, Wednesdays and Thursdays. This might be explained as the result of the fact that during both those hours and days there is an increased concentration of people going to work who might leave their bikes on the streets until the end of their shifts, providing crime opportunities to bike-thieves patrolling those areas. This assumption can be partially confirmed by the fact that $74 \%$ of bicycle thefts that occurred in those specific Tranges (between 2016-2018) happened outdoor. Adversely, Trange-b (19:00 - 22:30) risk values seemed to be particularly relevant for Fridays and Saturdays. The latter could be the consequence of a high number of people going out during weekends for leisure activities and leaving their bikes on the street. Indeed, almost $63 \%$ of thefts occurring in these Tranges (between 2016-2018) took place in District 1, 3 and 9 where the vast majority of clubs, restaurants and other commercial businesses tend to cluster. These results are in alinement with previous findings showing temporal distributions of other aoristic crimes such as residential burglaries (Weisel, 2002; Sorensen, 2004) and thefts of motor vehicles from city-centre 
parking facilities (Rengert, 1997, 210), which seemed to be shaped by similar routine activities. However, despite the relevant findings, Milan should be adopted as a case history leading to new studies (maybe involving different crime types) that might newly verified the predictive capacity of the Aoristic method.

\section{Conclusions}

To date, the present study provides the only empirical evidence in Italy as to the efficacy of Aoristic analysis method for aoristic crime, but these results are based on the study of only one crime type, namely bicycle theft. It is not certain that the present results are generalizable to other types of crime, but, pending further work, the routine activities approach suggests that they could be. Analysis of the crime reports used in this study showed that most bike-thefts occurred during the daytime while the victims were potentially at work and the nighttime while the victims were potentially out for leisure activities. It is likely that the routine activities of these victims have determined the distribution of bike-thefts within those Tranges.

However, further research is needed to verify if the findings here are applicable to other circumstances. Analysis of crimes that are not normally distributed in time may be particularly useful in testing whether the method described here is still applicable. Indeed, knowing when crimes occur is crucial to preventing them, but there are fewer techniques available for temporal analysis than for spatial analysis, where many techniques have been developed in the past two decades. In addition, there has not been sufficient research verifying the validity of temporal analysis at predicting and then preventing crimes.

In light of what has been stated so far, one of the key lessons of policing research is that intelligence resources for crime prevention should be led, indeed, by intelligence. Since most crimes are clustered in time, temporal analysis becomes crucial to ensure that the deployment of such resources is effective: without understanding how crimes distribute across time, officers cannot be in the correct place at the correct time to prevent them. Since many common crimes are aoristic, techniques such as the Aoristic analysis is crucial for ensuring an effective deployment of resources. Indeed, police officers who deliberately decide to avoid temporal analysis of crime patterns are potentially exposed to an ineffective deployment of resources, failing to prevent crime and undermining the status of intelligence-led policing.

\section{Aknowledgements}

I cannot express enough thanks to my collaborator for her continued support and encouragement: Dr. Cody Porter.

In addition, my completion of this research could not have been accomplished without the support of my research mates, Thomas, Rogier and Edoardo.

My heartfelt thanks.

\section{Conflict of Interest}

The author(s) declare(s) that there is no conflict of interest

\section{References}

1. Ashby, M. \& Bowers, K. (2013). A comparison of methods for temporal analysis of aoristic crime. Crime Science an Interdisciplinary Journal, 2(1), 1-16

2. Baumer E, Wright R (1996). Crime seasonality and serious scholarship: a comment on Farrell and Pease. British Journal of Criminology, 36(4):579-581

3. Brantingham PL, Brantingham PJ (1993). Nodes, paths and edges: considerations on the complexity of crime and the physical environment. Journal of Environmental Psychology, 13(1), 3-28

4. Censis (2018). 51' Rapporto sulla situazione sociale del Paese/2017. Milano: Franco Angeli

5. Cohen, L., E. \& Felson, M. (1979). Social Change and Crime Rate Trends: A Routine Activity Approach. American Sociological Review, 44(4), 588-608.

6. Cohn EG (1993). The prediction of police calls for service: the influence of weather and temporal variables on rape and domestic violence. Journal of Environmental Psychology, 13(2), 71-83

7. Cohn EG, Rotton J (2003). Even criminals take a holiday: instrumental and expressive crimes on major and minor holidays. Journal of Criminal Justice, 31(4), 351-360

8. da Silva, A. N. R., da Silva Costa, M., \& Macedo, M. H. (2008). Multiple views of sustainable urban mobility: The case of Brazil. Transport Policy, 15(6), 350-360. doi: 10.1016/j.tranpol.2008.12.003

9. Felson M (2006). Crime and Nature. Sage: Thousand Oaks

10. Felson M, Poulsen E (2003) Simple indicators of crime by time of day. International Journal of Forecasting, 19(4), 595-601

11. FIAB (2018). FIAB Milano. Retrieved from: https://www.fiabmilano.it/

12. Gakenheimer, R. (1999). Urban mobility in the developing world. Transportation Research Part A: Policy and Practice, 33(7-8), 671-689. doi: 10.1016/s09658564(99)00005-1

13. Gamman L, Thorpe A \& Willcocks M (2004). Bike off! Tracking the design and terrains of cycle parking: Reviewing use, misuse and abuse. Crime Prevention and Community Safety; 6(4), 19-36

14. Han, S. S. (2010). Managing motorization in sustainable transport planning: the Singapore experience. Journal of Transport Geography, 18(2), 314-321. doi: 10.1016/j.jtrangeo.2009.06.010

15. Harriss, D. J. \& Atkinson, G. (2011). Update - Ethical Standards in Sport and Exercise Science Research. International Journal of Sports Medicine, 32, 819-821

16. Jensen, P., Rouquier, J.-B., Ovtracht, N., \& Robardet, C. (2010). Characterizing the speed and paths of shared bicycle use in Lyon. Transportation Research Part D: Transport and Environment, 15(8), 522-524. doi: 10.1016/j.trd.2010.07.002

17. Johnson SD, Bowers KJ (2004). The stability of spacetime clusters of burglary. British Journal of Criminology, 44(1), 55-65

18. Johnson S. D., Sidebottom A. \& Thorpe A. (2008). Bicycle theft. Washington, DC: US Department of Justice.

19. Koetse, M. J., Rietveld, P. (2009). The impact of climate change and weather on transport: An overview of empirical findings. Transportation Research Part D: Transport and Environment, 14(3), 205-221 
20. Krimmel, J. and Mele, M. (1998), "Investigating stolen vehicle dump sites", Policing: An International Journal, 21(3), 479-489

21. Mburu, L., W. \& Helbich, M. (2016). Environmental Risk Factors influencing Bicycle Theft: A Spatial Analysis in London, UK. PLoS One, 11(9), 1-19. doi: 10.1371/journal.pone.0163354

22. McLaughlin LM, Johnson SD, Bowers KJ, Birks DJ, Pease K (2007). Police perceptions of the long- and shortterm spatial distribution of residential burglary. International Journal of Police Science and Management, 9(2):99-111

23. Melbin, M. (1978). Night as frontier. American Sociological Review, 43(1), 3-22

24. Messner SF, Tardiff K (1985) The social ecology of urban homicide: an application of the "routine activities" approach. Criminology, 23(2), 241-267

25. Montani, J., P., Schutz, Y. \& Dulloo, A., G. (2015). Dieting and weight cycling as risk factors for cardiometabolic diseases: who is really at risk? Obesity Reviews, 16(S1), 7-18.

26. Pucher, J., Dill, J., \& Handy, S. (2010). Infrastructure, programs, and policies to increase bicycling: An international review. [Review]. Preventive Medicine, 50, S106-S125. doi: 10.1016/j.ypmed.2009.07.028

27. Ratcliffe, J., H. (2000). Aoristic analysis: the spatial interpretation of unspecific temporal events. International Journal of Geographical Information Science, 14(7), 669679

28. Ratcliffe, J. H., and McCullagh, M. J., 1998, Aoristic crime analysis. International Journal of Geographical Information Science, 12, 751-764

29. Registro Italiano Bici (2019). Registro Italiano Bici. Retrieved from: https://beta.easytag.it/index.php

30. Rengert G (1997). Auto theft in central Philadelphia. In Policing for Prevention: Reducing Crime, Public Intoxication and Injury, no. 7 in Crime Prevention Studies series. Edited by: Homel R. Criminal Justice Press, NY; 199-219.

31. RUBBICI (2019). Rubbici: facciamola finita. Retrieved from: http://www.rubbici.it/

32. Richardson, B. C. (2005). Sustainable transport: analysis frameworks. Journal of Transport Geography, 13(1), 2939. doi: 10.1016/j.jtrangeo.2004.11.005

33. Rietveld, P., \& Daniel, V. (2004). Determinants of bicycle use: do municipal policies matter? Transportation Research Part A: Policy and Practice, 38(7), 531-550. doi: 10.1016/j.tra.2004.05.003

34. Savona, E., Dugato, M., Riccardi, M., Cuciniello, C., Maldi, F., Salvanelli, G. \& Tunesi, L. (2019). Retail Security in Europe: Going Beyond Shrinkage. Milano: Crime\&Tech (spin-off company of the Università Cattolica del Sacro Cuore - Transcrime)

35. Sidebottom A, Thorpe A. \& Johnson S., D. (2009). Using Targeted Publicity to Reduce Opportunities for Bicycle Theft: A Demonstration and Replication. European Journal of Criminology, 6(3), 267-286

36. Sorensen, D., W., M. (2004). Temporal Patterns of Danish Residential Burglary. Copenhagen, Justits Ministeriet

37. Sudhakara Reddy, B., \& Balachandra, P. (2012). Urban mobility: A comparative analysis of megacities of India. Transport Policy, 21(0), 152-164. doi: 10.1016/j.tranpol.2012.02.002

38. Vandenbulcke, G., Dujardin, C., Thomas, I., de Geus, B., Degraeuwe, B., Meeusen, R., \& Panis, L. I. (2011). Cycle commuting in Belgium: Spatial determinants and 'recycling' strategies. Transportation Research Part a-Policy and Practice, 45(2), 118-137. doi: 10.1016/j.tra.2010.11.004

39. Walker C (2009) Neighbor terrorism and the all-risks policing of terrorism. Journal of National Security Law and Policy, 3, 121-377

40. Weisel DL (2002). Burglary of Single-Family Houses. No. 18 in Problem-Oriented Guides for Police Series. US Department of Justice, Washington

41. Winter, M., Brauer, M., Setton, E.M., Teschke, K. (2010). Built environment influences on healthy transportation choices: bicycling versus driving. Journal of Urban Health, 87(6), 969-993. doi: 10.1007/s11524-0109509-6

42. Zhang L, Messner SF \& Liu J. (2007). Bicycle-Theft Victimization in Contemporary Urban China A Multilevel Assessment of Risk and Protective Factors. Journal of Research in Crime and Delinquency; 44(4): 406-426 